\title{
Successful Online Learning Experience: Perceptions of Chinese Undergraduate Students
}

\author{
$\mathrm{Li} \mathrm{Li}^{1}$ \& Jingya Zhang ${ }^{2}$ \\ ${ }^{1}$ School of English for International Business, Guangdong University of Foreign Studies, Guangzhou, China \\ ${ }^{2}$ Division of Business and Management, Beijing Normal University-HongKong Baptist University United \\ International College, Zhuhai, China \\ Correspondence: Li Li, School of English for International Business, Guangdong University of Foreign Studies, \\ Guangzhou, China. E-mail: 199110404@oamail.gdufs.edu.cn
}

Received: October 10, 2020 Accepted: January 10, 2021 Online Published: January 17, 2021

doi:10.5539/jel.v10n1p74 URL: https://doi.org/10.5539/jel.v10n1p74

\begin{abstract}
This study explores perceptions of Chinese undergraduate students taking online courses amid the Covid-19 pandemic. Using semi-structured interviews after students' completion of the online courses, the study yields certain findings. First, university administrators are expected to communicate more with students to hear their concerns and offer assistance accordingly. Second, instructors should incorporate more interactive activities to promote learning, create a relaxing learning environment, and provide a timely feedback to students. Third, undergraduate students should employ appropriate learning strategies that include: being an independent learner, making a self-regulated learning plan, managing time, and practicing self-motivation. Implications for online learning practices are discussed.
\end{abstract}

Keywords: online learning, traditional classroom learning, Covid-19 pandemic

\section{Introduction}

Due to the Covid-19 pandemic, educational institutions in China, ranging from primary schools to universities, are suggested to have online learning in the spring 2020 semester. Change from traditional classroom instruction to an online learning setting poses challenges to both instructors and students. It is the first time for most of them to access this new mode of teaching and learning. Moreover, they have to familiarize themselves with it in a short time and in a hasty manner. In addition, the pandemic puts people into a difficult situation. Did these challenges affect online teaching and learning? This study will focus solely on undergraduate students to examine their perceptions of online learning. As is known, a smooth adaptation to online learning is crucial for students as it has a great impact on their learning outcome. An in-depth understanding of students' perception will provide insight to higher education stakeholders.

There has been a wealth of research concerning online learning (Howland \& Moore, 2002; Allen \& Seaman, 2007; Zhang \& Zhang, 2009; Zhang \& Chen, 2018), most of which was conducted in the United States of America (USA). Buchanan, Wilson and Gopal (2008) and Al-Harthi (2010) noted that culture plays a role in the teaching and learning of online courses. This illustrates the need for more research in a different cultural context. As such, building on the contributions from previous research, this study aims to enrich the domain by exploring Chinese undergraduate student perceptions of online teaching and learning.

\section{Literature Review}

Online learning is often referred to as Web-based learning. It is an environment in which instructors and learners are geographically dispersed and interaction depends on electronic technology (Moore \& Kearsley, 1996). To date, research in online learning is multi-faceted (Hill \& Hannafin, 1997; Fredericksen et al., 2000; Howland \& Moore, 2002; Allen \& Seaman, 2007; Zhang \& Zhang, 2009; Zhang \& Chen, 2018; Liu et al., 2020; Shi, 2020; $\mathrm{Xu}, 2020)$. Research concerning online learning includes discussion of the comparison between traditional classroom and online learning. Zhang and Chen (2018) declared that online learning, compared with traditional classroom setting, tends to offer more educational resources to students and enables them to be free from the constraints of space and time. Xu (2020) took the school's core course Python programming and smart car technology as an example and proposed a hybrid teaching model based on high-quality MOOC (Massive Open 
Online Courses). She contended that both traditional and online teaching modes have their unique characteristics. For classroom teaching, instructors often focus on how to deliver content. Nonetheless, for online courses, instructors should put more emphasis on students' learning process to help them attain good learning outcomes. As such, it is suggested that instructors should modify their instructional design for online teaching. Other study posits that online and traditional instruction differ from each other significantly; instructors should consider the influencing factors of successful online teaching and learning (Kaufmann, Sellnow, \& Frisby, 2016).

Identification of factors that can influence students' effective online learning has been the focus of research for years (Harvey, 2000; Zhang \& Zhang, 2009; Kim, Song, \& Luo, 2016; Dziuban et al., 2018; Liu et al., 2020; Shi, 2020). Zhang and Zhang (2009) proposed a LICE model: learner, instructor, curriculum and environment, to explain the key factors that are crucial to effective online learning. Learner factor encompasses learner's learning strategy, learning motivation, learning styles and other individual characteristics. Instructor factor taps into instructor's perception of online teaching, instructional design, and teaching styles. Curriculum factor includes course content design, degree of interaction between instructor and student, and student and student. Environment factor involves a good online learning platform and necessary support offered to instructors and students. Each of these four dimensions encompassed in the model was examined specifically by other scholars. For instance, learner-related factors that impact online learning include learners' burnout (Zhao et al., 2018), time management disposition (Cai, 2012), goal orientation, self-efficacy, and learning engagement (Liao, 2011), and students' online learning strategy (Hill \& Hannafin, 1997). Vallade and Kaufmann (2018) investigated instructors' behavior in online course delivery and outlined behavior such as assigning unclear assignments, unclear course expectations, ineffective communication with students and lack of timely responses to students' emails as detrimental to online learning. As far as curriculum issue is concerned, it is noted that a positive connection between instructor and students (Dwyer et al., 2004), and constructive feedback from instructors, tend to foster a positive learning climate (Kerssen-Griep, Trees, \& Hess, 2008). With regard to environment, Zhu, Wang and $\mathrm{Du}(2020)$ argued that university administrators should formulate a holistic plan of online learning and offer timely and targeted assistance to instructors and students who have encountered problems such as discomfort with using computer and psychological stress caused by teaching and learning online.

In addition, research indicates public health emergency of international concern (PHEIC) often has negative impact on individuals and might decrease people's ability to function properly at work (Yi et al., 2010). Thus, it is inferred that online teaching and learning in the spring 2020 semester might have been impacted by the Covid-19 pandemic. University students were found to experience differing levels of depression and anxiety during the pandemic (Chang, Yuan, \& Wang, 2020). Such mental health issues are likely to cause a loss of interest in learning and negatively affect students' academic performance (Nail et al., 2015). What about the participants in this study? Has the online learning been affected by the pandemic? What sorts of difficulties have been encountered in this particular situation? To date, not much research has addressed online teaching and learning under emergency condition. As such, this study intends to examine the following questions based on student perceptions of taking online courses:

1) Do students perceive differences between traditional classroom and online learning?

2) What are perceived difficulties with online courses during the pandemic?

3) What issues are perceived by students to be effective to attain an optimal learning outcome?

\section{Methods}

\subsection{Design}

This case study takes a qualitative approach to examining university undergraduate students' experiences and perceptions of online learning. The selected methodology of semi-structured interview was used to elicit the first-hand experiences of students learning online (Cohen, Manion, \& Morrison, 2000). Interview questions mainly focused on three aspects: perceptions of online and classroom learning, difficulties with online learning and factors conducive to effective online learning. Interviews were conducted by WeChat (An app similar to WhatsApp) or in person based on interviewees' convenience; they were then audio recorded for accuracy. All interviews were done in Chinese. The interviews lasted approximately from 40 to 60 minutes. Verbatim transcripts were conducted after each interview. Authors first conducted data analysis independently and then had a discussion. Thematic content analysis was used to analyze data. First, each statement was coded with a label. Secondly, each statement was reevaluated to determine its relevance to the research question and the statements that are of little relevance to students' perception of online teaching and learning were eliminated. Thirdly, related labels were clustered into a new category and a thematic label was given to each new category. This step was conducted several times until core themes emerged. Lastly, the entire transcripts were reread to 
verify that the labels and themes were expressed by participants' words. The transcripts and the identification of the set of themes and final themes were all presented to the participants to determine whether the findings and interpretations were credible. Participants responded that the document accurately revealed their perceptions about online teaching and learning.

\subsection{Participants}

Participants in this study are Xin and Yi (both are pseudonyms). Both of them are female students. Xin is from a university situated in the eastern part of China. This is a key university in China. Xin majors in material chemistry and is currently a third-year student. Yi is a fourth-year student in the university located in the southern part of China. Yi majors in human resource management. Two students were selected purposively. They were in different majors, arts and sciences. They had been studying at university for over two years. In addition, they worked hard and their academic achievement was good. Both of them took at least six online courses in the spring 2020 semester and were willing to take part in the study to reflect on their perceptions of learning online.

\section{Results}

Three central themes emerged from students' online learning experiences, including (1) perception of online and classroom learning, (2) perceived problems and difficulties with online courses, and (3) factors perceived to be crucial for effective learning outcome.

\subsection{Perception of Online and Classroom Learning}

When asked whether any perceived differences exist between traditional classroom and online learning, participants tended to present a very similar answer to this question. Both participants framed the discussion concerning the pedagogical design of the course, assignment structure, assessment strategy, and students' behavior in lectures (See Table 1). As far as pedagogical design of the course is concerned, both of them mentioned that they perceived no significant difference in the way teachers delivered their lectures. Xin mentioned:

In traditional classroom setting, it is the tutor that plays a key role. He does most of the lectures, followed by some exercises. Maybe it is because of the subject content, the same pattern is found among most of the tutors in online teaching.

Yi majored in management. She also stated that most of her tutors followed the same teaching pattern when teaching online. When asked whether there was any impact of such online teaching style on their learning, both participants declared it was ok, yet suggested minor changes should be made to online teaching. In terms of assignment structure, participants offered similar answers. No big difference has been found between traditional classroom and online assignment structure. Yi's assignment consisted of individual work and group project while Xin's assignment was mainly to do individual work. Considering instructors' assessment strategy, both participants pointed out that most instructors preferred open-book exam. Xin commented: "In traditional teaching setting, we have unseen exams for all courses. However, we have open-book exams for all courses this term." Yi encountered a slightly different situation. Yi said: "we have open-book exams. In addition, for some courses, we are supposed to submit a report or finish a project." Both participants felt comfortable with the assessment strategy. Nonetheless, both of them noted that supervision of student behavior in the lecture was the issue perceived to be the significant difference between online and classroom learning. Xin said:

Unlike classroom learning, online learning lacks mechanism to monitor whether students are taking the lecture or not. Some of my classmates played computer games or did something else during lecture time. When instructor concluded a lecture, some of them even said the lecture time passed so quickly.

Yi depicted the same picture with some of her classmates. In addition, Yi declared that students were more likely to be distracted when learning online and this held true even for hard-working students:

Distraction may be due to instructor's lengthy lecture or students' physical or psychological state or other issues. In classroom learning environment, when I encountered distractions, instructor and other hard-working students might pose a pressure to take me back on track. However, for online learning environment, I study alone. No one will tell me to concentrate on the course. It is much easier to get distracted during the online lectures. (Yi) 
Table 1. Perception of difference between online and classroom learning

\begin{tabular}{ll}
\hline Findings \\
\hline - & No significant change in instructors' pedagogical design and assignment structure, \\
- & Slight changes in assessment strategy with most courses having open-book exams, \\
- & Biggest question is lack of supervision of student behavior
\end{tabular}

\subsection{Perceived Problems and Difficulties with Online Courses}

Being compelled to learn online in a hasty manner, participants might have come across difficulties and setbacks. When asked to discuss the impact of the pandemic on the learning, Xin raised the following issues: 1) student experienced psychological stress when first knowing they would have online learning this term, 2) university staff did not provide sufficient support to students at the start of the semester, and 3) it took a long time for some students to adjust to this new learning mode. Xin stated:

Before the start of this spring term, we assumed that we won't have lectures until we could return to campus. All of a sudden, university notified us we were going to take courses online. On hearing the notice, most of us experienced bewilderment, worry, and were completely at a loss. Except for the notice that we were going to have online lectures, we students did not get any other assistance from the university. I think the university could do more to prepare students for this new mode of learning.

Additionally, it took a relatively long time for students to get accustomed to this new instructional mode.

It took us four to six weeks to adjust to this new learning mode. For some of my courses, note-taking is crucial. In classroom learning setting, instructors will slow their pace when we take notes. However, in a virtual learning environment, it is difficult for instructors to monitor the pace. In the first several weeks, most of us were not able to follow instructor's lecture pace to take notes. By communicating with instructors and also by enhancing note-taking skills, the problem was resolved finally. Basically speaking, the first six weeks are difficult for most of us. Later, we seem to adapt to online courses. (Xin)

Adjusting to online learning also creates problems to Yi, especially during the pandemic. She said:

Due to social distancing policy practiced everywhere, we have to stay at home for most of the time. This is really distressing. Previously, when I felt stressful or when I got a difficult assignment done, I often went with my friends to restaurants near the campus. This is a good way for me to relieve pressure. Currently, dining with friends is impossible. Staying at home is so boring. I feel tired with learning from home. (Yi)

In addition, Yi thought the learning effectiveness was undermined. "The learning outcome is discounted. I work hard in classroom setting. When I have courses online, there are so many distractions that can hinder me from concentrating on my study." Moreover, Yi mentioned that lack of diverse classroom activity was another factor that caused her loss of interest in online courses. "Previously, we have individual or group presentation, case study, and group discussion in most lectures. Now with online learning, most of the learning activities have been cancelled." Apart from the aforementioned issues, Yi, as well as Xin, pointed out that some tutors were not skillful at using online teaching tools and there was temporary network disconnection. What is more, both participants complained that online learning burdened them in terms of increased learning time and assignment overload. Participants' viewpoints are summarized in Table 2.

Table 2. Perceived problems and difficulties with online courses

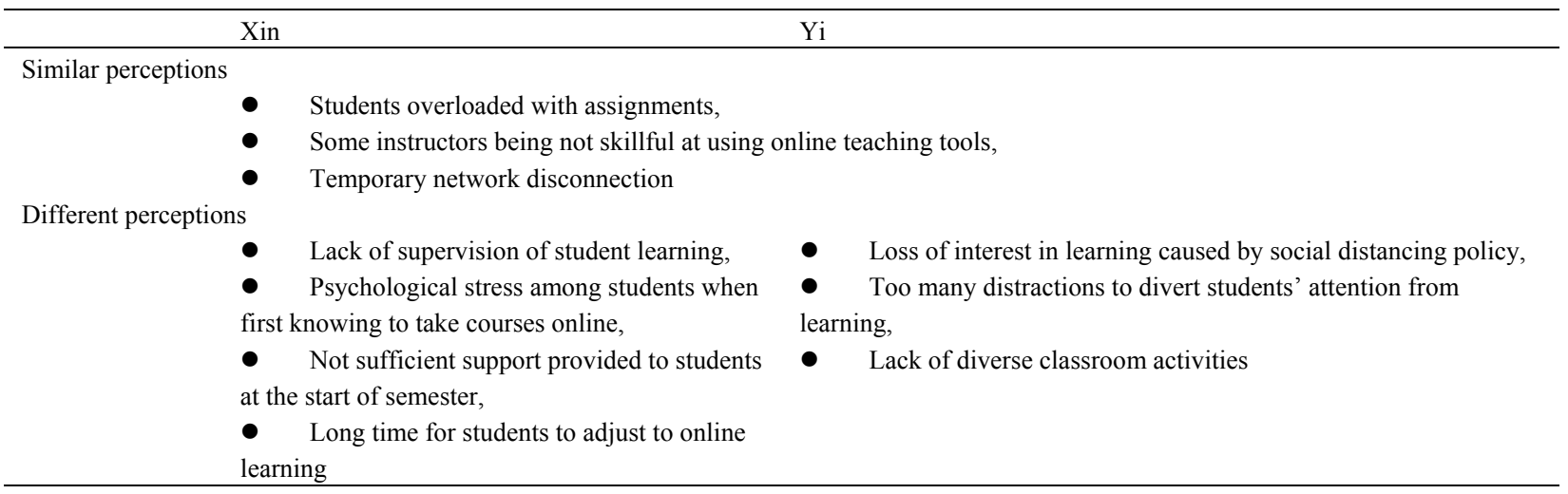




\subsection{Factors Perceived to be Crucial for Effective Learning Outcome}

Participants were asked to highlight the factors they perceived to be crucial for effective online learning outcome. Both instructor- and student-related factors were discussed by participants. Both participants suggested that instructors should facilitate students' learning in online courses rather than just deliver a lecture. They stated that they did not like instructors doing all the talk during lecture time. Moreover, instructors were expected to design some questions, pose the questions and invite students to answer them during the lecture.

This is a good way to keep students focused on the lecture. In addition, it is a good way for students to present themselves. (Yi)

When students give correct answer to the question, it is a very effective way to motivate students. Moreover, this can promote communication between instructor and students, and between students and students. (Xin)

Additionally, two participants had differing views of effective online teaching and learning. Yi appreciated the timely responses from instructors, saying:

During online learning period, we have easy access to instructor's contact information. Previously, we only have instructors' email address. Questions in email usually were not answered within a day. Some of them were even unanswered. Now, we put question in WeChat and can get a quicker response from instructor, compared to that in email. Instructor's timely feedback can help us clarify certain doubts and give us more confidence in learning. (Yi)

Xin summarized three instructor-related factors she perceived to be effective for optimal learning outcome:

If instructors use videos and animation when explaining some complicated concepts or theories, students can grasp the learning content in a much easier way. In addition, we like instructors who often use network buzzwords to add gentle humor to lectures. It is a good way to narrow the distance between instructor and students. We also like instructors using a webcam during lecture time. This gives us an impression that the instructor is approachable. (Xin)

With regard to student-related factors that are crucial for successful learning outcome, Yi stated:

Students should be very self-disciplined in online learning as there is a variety of distractions that can hinder their focus on learning. Students should also learn to be responsible for their learning. For instance, with the increased workloads, students should learn to accept the challenge and find strategies to overcome the challenge rather than give up. Moreover, students should learn to seek help from instructors and classmates. In classroom learning, it is much easier to obtain help from instructors and other students. Now with online learning, when we encounter problems, it might be a little difficult for some of the students to turn to instructors or classmates for help because some may consider such help-seeking behavior as face-losing. However, my suggestion is that in order to achieve an optimal learning outcome, we should be brave to seek help from them (instructors and classmates) when we have any questions we cannot resolve by ourselves. (Yi)

Xin expressed her views of student-related factors conducive to an optimal learning outcome. Her suggestions included: (1) being a self-regulated learner, (2) doing a good time management, and (3) practicing self-motivation. She shared:

First, we should learn to monitor our own learning. I always preview the lecture, take notes during the lecture and review after the lecture. In addition, I use different learning strategies with different courses. This works very well, in particular, for those courses piled up with complicated theories or concepts. Secondly, it is crucial for us to know what you are going to do every day. Now that we are studying at home, it is easy to idle the days away. To guarantee a good learning outcome, I have a daily to-do list of activities with specific time attached to each activity. This tells me to follow the schedule and by the end of the day you will be very satisfied with the work you have done for the day. Thirdly, taking courses online, to some extent, is more likely to make us lose some interest in learning. This is definitely very bad. During this term of studying from home, I have read 3 autobiographies of successful businessmen and military leader. When I experience boredom or loss of interest in my learning, I reflect on the stories from those autobiographies. They are really inspiring. (Xin)

Table 3 summarizes the factors perceived to be crucial for effective online learning outcome. 
Table 3. Factors perceived to be crucial for effective online learning outcome

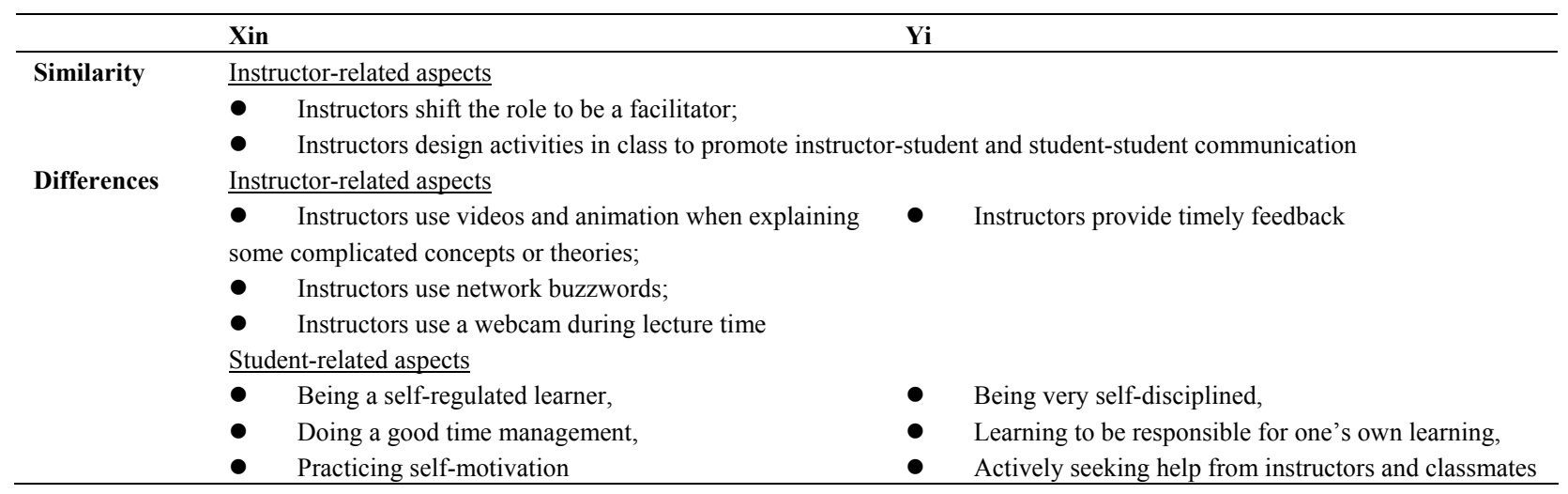

\section{Discussion}

This case study explored the perceptions of Chinese undergraduate students taking online courses in face of Covid-19 pandemic. Data concerning the first research question showed that basically students did not perceive significant differences between classroom and online learning. This is consistent with prior research (Xu, 2020). However, this does not mean that online teaching is just the change in place, time or technology. For effective teaching and learning to take place, data revealed that both instructors and students need to make the effort. As far as instructor-related issues are concerned, first, instructors are expected to shift the role to be a facilitator. This indicates that students desire a more learner-centered approach in online courses. Learner-centered approach has the potential to help learners foster essential learning skills and correlates with long-term student achievement in a positive manner (Derting \& Ebert-May, 2010). Secondly, instructors should incorporate more interactive activities in the pedagogical design of online courses. This aligns with previous research (Yew \& Goh, 2016) outlining the importance and benefits of well-planned interactive activities. In particular, problem-based learning (PBL) is considered to improve students' problem-solving skills and contributes to long-term knowledge memory (Yew \& Goh, 2016; Argaw et al., 2017). Thirdly, instructors who took measures to approach students (for instance, using network buzzword, or using a webcam during lecturing) were perceived to contribute to an effective learning environment. This echoes Yang's (2006) and Xu's (2009) viewpoint that creating a relaxing learning environment has the potential to relieve learners' psychological stress and to enhance learner self-efficacy. Fourthly, learners expect timely feedback from instructors. This is in line with Northrup's (2002) and Xu's (2009) argument that instructor's timely feedback is considered essential for successful online courses. In addition to instructor's effort put into online teaching, our findings suggest that students are also supposed to play a role in the transition to online learning. The data indicates the importance of self-regulated learning strategy employed by students (Holec, 1981). For effective learning outcome to be achieved, it is highly recommended that students should be self-disciplined, take responsibility for their learning, actively seek help when needed, make a detailed plan for subject learning, do a good time management and practice self-motivation.

\section{Conclusion}

This study addresses perceptions of undergraduate students taking online courses. Considering the limited sample size, generalization of results should be drawn in a careful manner. However, the results of this study might be transferred to people who regard the situation similar to their context. Further study could use a quantitative method to measure students' learning outcome or reaction to online courses.

This study has implications for online course practices. For university administrators, when deciding to make a transition from one teaching mode to another, more communication should be conducted with students to hear their concerns and more assistance should be provided to students. For instructors teaching online courses, it is suggested that they should consider taking a more student-centered approach to pedagogical design, incorporating more interactive activities to promote learning, creating a relaxing learning environment, and providing a timely feedback to students. For undergraduate students to achieve a successful learning outcome, certain learning strategies should be adopted. Strategies involve: being an independent learner, seeking help when necessary, making self-regulated learning plan, managing time, and practicing self-motivation. 


\section{References}

Al-Harthi, A. S. (2010). Cultural differences in transactional distance preference by Arab and American distance learners. Quarterly Review of Distance Education, 11(4), 257-267.

Allen, I. E., \& Seaman, J. (2007). Online Nation: Five Years of Growth in Online Learning. ERIC.

Argaw, A. S., Haile, B. B., Ayalew, B. T., \& Kuma, S. G. (2017). The Effect of Problem Based Learning (PBL) Instruction on Students' Motivation and Problem-Solving Skills of Physics. EURASIA Journal of Mathematics, Science \& Technology Education, 13(3), 857-871. https://doi.org/10.12973/eurasia.2017.00647a

Buchanan, J., Wilson, S. T., \& Gopal, N. (2008). A cross cultural virtual learning environment for students to explore the issue of racism: A case study involving the UK, USA and SA. Social Work Education, 27(6), 671-682. https://doi.org/10.1080/02615470802201804

Cai, R., \& Zhou, S. J. (2012). Relationship between Internet Self-efficacy and Time Management Disposition in College Students. Chinese Journal of Clinical Psychology, 20(2), $249-251$. https://doi.org/10.16128/j.cnki.1005-3611.2012.02.014

Chang, J. H., Yuan, Y. X., \& Wang, D. (2020). Mental health status and its influencing factors among college students during the epidemic of COVID-19. J. South Med. Univ., 40(2), 171-176. https://doi.org/10.12122/j.issn.1673-4254.2020.02.06

Cohen, L., Manion, L., \& Morrison, K. (2000). Research Methods in Education (5th ed.). London: Routledge Falmer.

Derting, T. L., \& Ebert-May, D. (2010). Learner-centered inquiry in undergraduate biology: Positive relationships with long-term student achievement. Cell Biology Education-Life Sciences Education, 9 (Winter), 462-472. https://doi.org/10.1187/cbe.10-02-0011

Dwyer, K. K., Bingham, S. G., Carlson, R. E., Prisbell, M., Cruz, A. M., \& Fus, D. A. (2004). Communication and connectedness in the classroom: Development of the connected classroom climate inventory. Communication Research Reports, 21, 264-272. https://doi.org/10.1080/08824090409359988

Dziuban, C., Graham, C. R., Moskol, P., Norberg, A., \& Sicilia, N. (2018). Blended learning: The new normal and emerging technologies. International Journal of Education Technology in Higher Education, 15, 1-16. https://doi.org/10.1186/s41239-017-0087-5

Fredericksen, E., Pickett, A., Shea, P., Pelz, W., \& Swan, K. (2000). Factors influencing faculty satisfaction with asynchronous teaching and learning in the SUNY learning network. Journal of Asynchronous Learning Networks, 4(3), 245-278. https://doi.org/10.24059/olj.v4i3.1897

Harvey, V. (2000). Engaging students in interactive online teaching. Communication Teacher, 15(1), 7-10.

Hill, J. R., \& Hannafin, M. J. (1997). Cognitive strategies and learning from the World Wide Web. Educational Technology Research and Development, 45(4), 37-64. https://doi.org/10.1007/BF02299682

Holec, H. (1981). Autonomy and Foreign Language Learning. Oxford Pergamon Press.

Howland, J. L., \& Moore, J. L. (2002). Student perceptions as distance learners in Internet-Based courses. Distance Education, 23(2), 183-195. https://doi.org/10.1080/0158791022000009196

Kaufmann, R., Sellnow, D. D., \& Frisby, B. N. (2016). The development and validation of the online learning climate scale (OLCS). Communication Education, 65(3), $307-321$. https://doi.org/10.1080/03634523.2015.1101778

Kerssen-Griep, J., Trees, A. R., \& Hess, J. A. (2008). Attentive facework during instructional feedback: Key to perceiving mentorship and an optimal learning environment. Communication Education, 57, $312-332$. https://doi.org/10.1080/03634520802027347

Kim, J., Song, H., \& Luo, W. (2016). Broadening the understanding of social presence: Implications and contributions to the mediated communication and online education. Computers in Human Behavior, 65, 672-679. https://doi.org/10.1016/j.chb.2016.07.009

Liao, Y. G. (2011). College Students' Academic Self-efficacy Effects on their Learning Value and Engagement. Journal of Ningbo University (Educational Science Edition), 33(5), 50-54.

Liu, Y. Q., Zhou, L. J., Wei, H. Y., \& Yin, Q. (2020). Analysis of Current Situation and Satisfaction of College Students' Online Learning. University Education, 1, 192-194. 
Moore, M. G., \& Kearsley, G. (1996). Distance education: A systems view. Belmont, CA: Wadsworth.

Nail, J. E., Christofferson, J., Ginsburg, G., Drake, K., Kendall, P. C., McCracken, J. T., ... Sakolsky, D. (2015). Academic impairment and impact of treatments among youth with anxiety disorders. Child \& Youth Care Forum, 44(3), 327-342. https://doi.org/10.1007/s10566-014-9290-x

Northrup, P. T. (2002). Online learners' preferences for interaction. The Quarterly Review of Distance Education, $3(2), 219-226$.

Shi, H. B. (2020). Analysis of Satisfaction with Online Teaching. HeiLongJiang Education, 9, 66-67.

Vallade, J. I., \& Kaufmann, R. (2018). Investigating instructor misbehavior in the online classroom. Communication Education, 67(3), 363-381. https://doi.org/10.1080/03634523.2018.1467027

$\mathrm{Xu}, \mathrm{G}$. Y. (2020). Design and practice of distance teaching based on the theory of learning effectiveness pyramid. Computer Education, 6, 17-20.

Xu, Y. (2009). Reflection on the Methods of Fostering Self-Efficacy. Education and Administration, 2, 18-19.

Yang, G. X. (2006). Influencing Factors and Cultivation of College Students' Self-efficacy. Psychological Health Development, 26, 75-76.

Yew, E. H. J., \& Goh, K. (2016). Problem-Based Learning: An Overview of Its Process and Impact on Learning. Health Professions Education, 2(2), 75-79. https://doi.org/10.1016/j.hpe.2016.01.004

Yi, L., Wang, Z. C., Jiang, Z. K., Zheng, Y. J., \& Wu, W. Z. (2010). Research progress of psychological intervention in public health emergencies. China J. Public Health, 26(7), 929-930.

Zhang, B. Y., \& Chen, Q. (2018). Analysis of application of online teaching mode. Educational Information Technology, 11, 61-63.

Zhang, J. H., \& Zhang, J. P. (2009). Factors influencing online learning and LICE model. Audio-Visual Education Research, 6, 73-77.

Zhao, C. L., Li, H. X., Jiang, Z. H., \& Huang, Y. (2018). Alleviating Online Learners' Burnout: A Study on the Influence of Teachers' Emotional Support. Distance Education and Online Learning, 2, 29-36.

Zhu, L. C., Wang, N., \& Du, Y. T. (2020). Research on the Influencing Factors and Promotion Strategies of Online Learning Satisfaction of College Students. Journal of National Academy of Education Administration, 5, 82-88.

\section{Copyrights}

Copyright for this article is retained by the author, with first publication rights granted to the journal.

This is an open-access article distributed under the terms and conditions of the Creative Commons Attribution license (http://creativecommons.org/licenses/by/4.0/). 